\title{
NOTA SOBRE UM CORRENTOMETRO DE PÊNDULO UTILIZADO PELO CHESAPEAKE BAY INSTITUTE (TECHNICAL REPORT N.० 1)
}

\author{
Tradução e adaptação de \\ Paulo de Castro Moreira da Silva \\ Capitão de Corveta - Diretoria de Hidrografia e Navegação
}

1 - A medição da direção e da velocidade da corrente a várias profundidades, essencial para o conhecimento do "campo cinemático", é geralmente dificultada pelo alto preço e pela complexidade dos correntômetros clássicos. Os oceanógrafos do Chesapeake Bay Institute - que trabalham para a Marinha Americana - acabam de divulgar um processo novo, simples, barato e, entretanto, rigoroso, que aplicaram, com sucesso, a esta operação.

2 - O método não é, em princípio, novo, mas introduz uma soluȩão feliz, que dispensa as incômodas calibragens. Se um pêndulo (fig. 1) é exposto a uma corrente, êle é desviado da vertical por uma fôrça:

$$
\mathrm{F}=\mathrm{C}_{\mathrm{d}} \cdot \mathrm{A} \cdot \rho \frac{v^{2}}{2}
$$

sendo $v$ a velocidade da corrente, $A$ a secção reta do corpo do pêndulo em relação a ela, $\mathrm{C}_{d}$ o coeficiente de arrastamento, que depende da forma do corpo e do número de Reynolds $(\mathrm{R})$; $\rho$ a densidade do fluído. O pêndulo se inclina, assim, até um ângulo $\theta$, quando $F$ é equilibrado pela fôrça restauradora da gravidade sôbre o pêndulo.

Tem-se, então, (fig. 1) :

ou

$$
\begin{aligned}
& \operatorname{tg} \theta=\frac{\mathrm{F}}{\mathrm{mg}}=\frac{\mathrm{C}_{\mathrm{d}} \mathrm{A} \rho \mathrm{v}^{2}}{2 \mathrm{mg}}, \\
& \mathrm{v}=\sqrt{\frac{2 \mathrm{mg}}{\mathrm{C}_{\mathrm{d}} \mathrm{A} \rho}} \sqrt{\operatorname{tg} \theta}
\end{aligned}
$$

Para que entre a velocidade da corrente $(v)$ e a inclinação do pêndulo, $\theta$, exista uma relação simples, tabulável, é necessário que o primeiro fator, que chamamos $k$, seja constante (pelo menos dentro do campo de va- 
riação de $v$ que se deseja medir). Para que $k$ seja constante, é necessário que $\mathrm{C}_{\mathrm{d}}$ o seja. $\mathrm{C}_{\mathrm{d}}$ depende, como dissemos, da forma do corpo e do número de Reynolds. Foi determinado que para um pêndulo feito de placas planas, em cruz - e euja relação comprimento-largura esteja entre 1 e 5 - e para os valores de $v$ que se espera medir, $\mathrm{C}_{\mathrm{d}}$ pode ser considerado constante $\mathrm{e}$ igual a 1,2. Desta forma, para um pêndulo nessas condições, é possível deduzir teóricamente, $v$ de $\theta$, o que evita a calibragem.

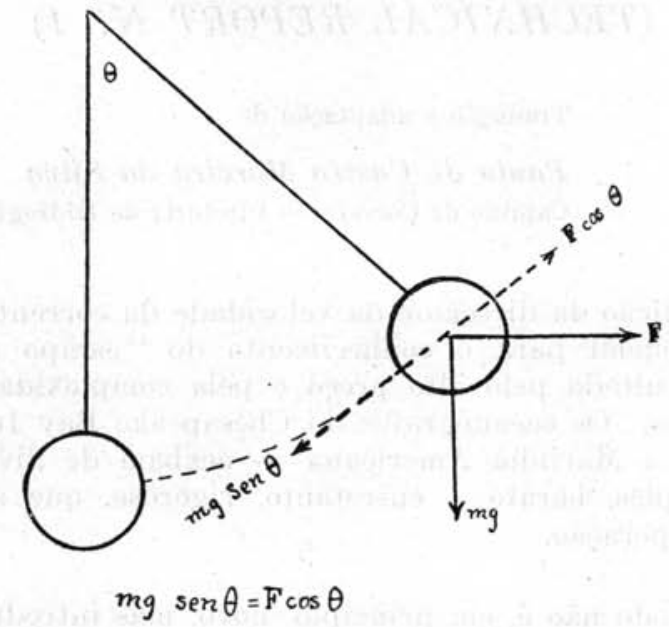

Fig. 1

3 - Conseqüentemente, os norte-americanos construíram biplanos em eruz, de abeto compensado (cineo fôlhas, meia polegada de espessura, no total), em duas dimensões-padrão, como se verá a seguir (fig. 3 e 4); e os usam da maneira seguinte (fig. 2):

O biplano é suspenso a um fio de sonda (o mais fino possível), que passa por um moitão, a certa distância do navio fundeado e é convenientemente lastrado. O biplano é descido à profundidade desejada. Com um transferidor (fig. 5) se mede o ângulo $\theta$. É medido também o ângulo que a projeção horizontal do fio faz com a prôa do navio (direção da corrente. De $\theta$ se deduz a velocidade da corrente, $v$.

Os norte-americanos utilizam dois modelos de biplanos: de $2 \times 3$ pés, e de 1 x 1,5 pés - ambos podendo ser lastrados com 30 ou $15 \mathrm{lb}$. (figs. 3 e 4). O pêso dêssēs modelos dentro d'água, depois de lastrados, é o seguinte $\left({ }^{1}\right)$ :

(1) Outros biplanos, das mesmas dimensões, exibindo, dentro d’água, com o lastro, o mesmo pêso total que os modelos abaixo, são perfeitamente satisfatórios. Pode-se, pois, fabricar os biplanos e depois lastrá-los o suficiente para obter o mesmo pêso total. 
Modêlo grande c/ lastro de $15 \mathrm{lb}$ : : 8,25 lb.

Modêlo grande c/ lastro de $30 \mathrm{lb}$ : : $22 \mathrm{lb}$.

Modêlo pequeno c/ lastro de $15 \mathrm{lb}$ : : 12,50 lb.

Modêlo pequeno c/ lastro de $30 \mathrm{lb}$. : 26,75 lb.

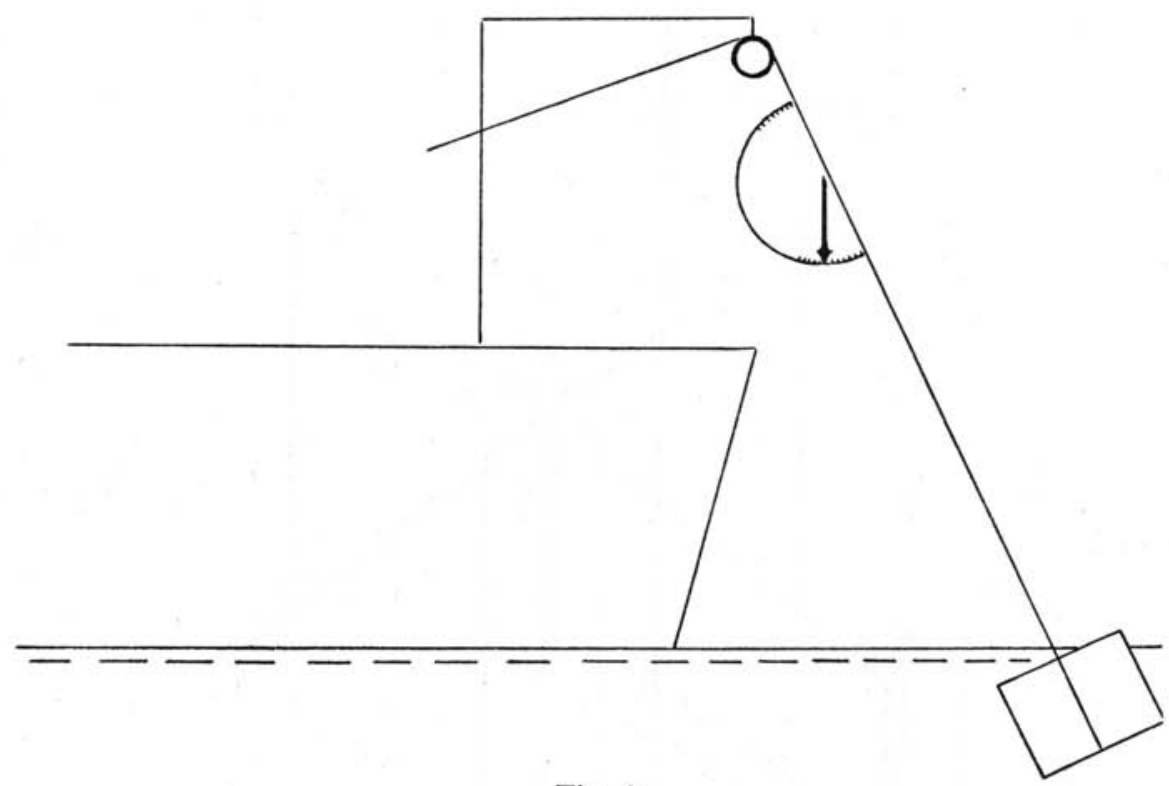

Fig. 2

Tomando-se para $g$ o valor 32 pés/sg/sg, para o valor médio 63 $\mathrm{lb} / \mathrm{pe}^{3}$, para $\mathrm{C}_{\mathrm{d}}$ o valor 1,2 é fácil deduzir $k$. Chega-se, assim, às fórmulas :

$$
\begin{aligned}
& \mathrm{v}_{\text {nós }}=0,64 \sqrt{\operatorname{tg} \theta} \\
& \text { Modêlo grande }(22 \quad \mathrm{lb}):{ }^{{ }^{p e ́ s / s g}}=1,76 \sqrt{\operatorname{tg} \theta} \\
& \mathrm{v}_{\text {nós }}=1,04 \sqrt{\operatorname{tg} \theta} \\
& \text { Modêlo pequeno }(12,50 \mathrm{lb}):{ }^{\mathrm{pés}_{\mathrm{sg}}}=2,65 \sqrt{\operatorname{tg} \theta} \\
& \mathrm{v}_{\text {nós }}=1,57 \sqrt{\operatorname{tg} \theta} \\
& \text { Modêlo pequeno }(26,75 \mathrm{lb}):{ }^{{ }^{p e ́ s / s g ~}}=3,88 \sqrt{\operatorname{tg} \theta} \\
& \mathrm{v}_{\text {nós }}=2,30 \sqrt{\operatorname{tg} \theta}
\end{aligned}
$$




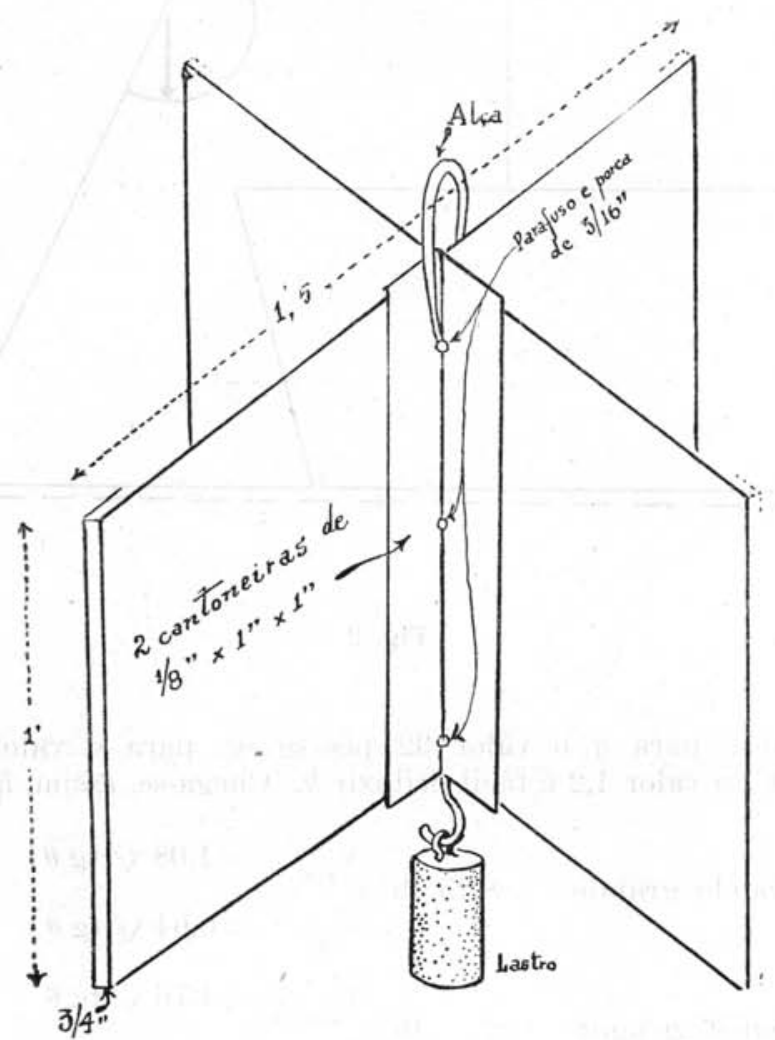

Fig. 3 


$$
\square 9
$$


Em anexo, são dadas tabelas calculadas para tais pêndulos.

Cuidados: Para que a madeira não se empape d’água, o que falsearia as tabelas, deve-se usar abeto impermeável, pintado. fio fino.

Para que o fio não ofereça à corrente grande resistência, deve-se usar

TABELAS

Modêlo $2 \times 3$ ', pesando $8,25 \mathrm{lb}$ dentro d'água.

VELOCIDADE EM NÓS

$\begin{array}{rrccccccccc}\theta & 0 & 1 & 2 & 3 & 4 & 5 & 6 & 7 & 8 & 9 \\ 0 & 0 & 0,08 & 0,12 & 0,15 & 0,17 & 0,19 & 0,20 & 0,22 & 0,24 & 0,26 \\ 10 & 0,27 & 0,28 & 0,29 & 0,31 & 0,32 & 0,33 & 0,34 & 0,35 & 0,37 & 0,38 \\ 20 & 0,39 & 0,40 & 0,41 & 0,42 & 0,43 & 0,44 & 0,45 & 0,46 & 0,47 & 0,48 \\ 30 & 0,49 & 0,50 & 0,51 & 0,52 & 0,53 & 0,54 & 0,55 & 0,56 & 0,57 & 0,58 \\ 40 & 0,59 & 0,60 & 0,61 & 0,62 & 0,63 & 0,64 & 0,65 & 0,66 & 0,67 & 0,69\end{array}$

Modêlo $2 \times 3$ ', pesando $22 \mathrm{lb}$ dentro d'água.

$\begin{array}{rrrllllllll}0 & 0 & 0,14 & 0,20 & 0,24 & 0,28 & 0,31 & 0,33 & 0,37 & 0,39 & 0,42 \\ 10 & 0,44 & 0,46 & 0,48 & 0,50 & 0,52 & 0,54 & 0,56 & 0,58 & 0,60 & 0,62 \\ 20 & 0,63 & 0,65 & 0,67 & 0,69 & 0,70 & 0,72 & 0,73 & 0,75 & 0,77 & 0,78 \\ 30 & 0,80 & 0,81 & 0,83 & 0,85 & 0,86 & 0,88 & 0,90 & 0,91 & 0,93 & 0,95 \\ 40 & 0,96 & 0,98 & 1,00 & 1,01 & 1,03 & 1,05 & 1,07 & 1,09 & 1,11 & 1,13\end{array}$

Modêlo 1 x 1,5', pesando $12,5 \mathrm{lb}$ dentro d'água.

$\begin{array}{rrrrrrrrrrr}0 & 0 & 0,21 & 0,29 & 0,36 & 0,42 & 0,47 & 0,50 & 0,55 & 0,59 & 0,63 \\ 10 & 0,66 & 0,69 & 0,72 & 0,75 & 0,78 & 0,81 & 0,84 & 0,87 & 0,90 & 0,92 \\ 20 & 0,95 & 0,97 & 1,00 & 1,02 & 1,05 & 1,07 & 1,10 & 1,12 & 1,15 & 1,17 \\ 30 & 1,19 & 1,22 & 1,24 & 1,27 & 1,29 & 1,31 & 1,34 & 1,36 & 1,39 & 1,41 \\ 40 & 1,44 & 1,46 & 1,49 & 1,52 & 1,54 & 1,57 & 1,60 & 1,63 & 1,66 & 1,68\end{array}$

Modêlo $1 \times 1,5$ ', pesando 26,75 lb dentro d’água.

$\begin{array}{rrrrrrrrrrr}0 & 0 & 0,30 & 0,43 & 0,53 & 0,61 & 0,68 & 0,73 & 0,81 & 0,86 & 0,92 \\ 10 & 0,97 & 1,01 & 1,06 & 1,10 & 1,15 & 1,19 & 1,23 & 1,27 & 1,31 & 1,35 \\ 20 & 1,39 & 1,43 & 1,46 & 1,50 & 1,53 & 1,57 & 1,61 & 1,64 & 1,68 & 1,71 \\ 30 & 1,75 & 1,78 & 1,82 & 1,85 & 1,89 & 1,92 & 1,96 & 2,00 & 2,03 & 2,07 \\ 40 & 2,11 & 2,14 & 2,18 & 2,22 & 2,26 & 2,30 & 2,34 & 2,38 & 2,42 & 2,47\end{array}$

NOTA: As Tabelas são rigorosamente válidas até uma profundidade de 50 pés, mas se o fio fôr fino (corda de piano, por exemplo), poderão ser usadas para profundidades bem maiores. 